\title{
Design and Analysis of Mounting Arrangement of the Rotary Turbine Control (RTC) Drive System
}

\author{
Prajakta Raosaheb Yadav ${ }^{(1)}$, Prof. S. H. Limaye ${ }^{(2)}$, Smita K Nandargi ${ }^{(3)}$, Monali Gulame ${ }^{(4)}$ \\ ${ }^{(1)}$ M. Tech Final Year Student, Department of Mechanical Engineering, Walchand College of Engineering, Sangli, India. \\ (2) Project Guide, Department of Mechanical Engineering, Walchand College of Engineering, Sangli, India. \\ (3), (4) Company Project Guides, Cummins Turbo Technology, Cummins Technical Centre India, Pune.
}

\begin{abstract}
Turbocharger is the turbine driven force induction device widely used in IC engine applications to meet performance and emission requirement. The Rotary Turbine Control (RTC) system is the invention of Cummins in turbotechnology field. The components of system are RTC valve, actuator and RTC linkage. The RTC linkage contains lever arm and spring and it connects actuator shaft and RTC valve shaft. Actuator rotates valve by using linkage. RTC valve manipulates the exhaust gas going in the turbine housing. This valve is actuated by Engine Control Module (ECM) through the actuator. ECM unit sends signal to actuator depending on the road condition and then actuator rotates valve by using RTC linkage. This paper has 2 goals. First is to design bracket to support actuator on turbine housing in the given space claim and validated design of bracket by modal analysis and RVA for given conditions. As all RTC system components are close to turbine housing so they are exposed to high temperature. The actuator and spring are very temperature sensitive. So, second goal is designing of heat shield for actuator and spring and validate these designs by using Steady thermal analysis for given temperature conditions.
\end{abstract}

Keywords - Turbocharger, Turbine Housing (TH), Rotary Turbine Control (RTC), Cause and Effect matrix (CnE), Modal Analysis, Power Spectral Density (PSD)

\section{INTRODUCTION}

Cummins Company has many generations of turbocharger. According to recent emission norms, the exhaust gases coming out of engine should be minimum as possible. To meet this condition Cummins introduces RTC system to automobile industry.

RTC valve is placed at the inlet manifold of the turbocharger in the turbine housing ss shown in the fig. 1.1. by red dot. This valve manipulates exhaust gases before going into the turbine housing. The components of RTC system are RTC valve, RTC linkage and actuator. RTC valve manipulate the exhaust gas. RTC linkage connects valve shaft and actuator shaft and actuator rotate valve by using RTC linkage. According to road and engine condition, Engine Control Module (ECM) sends signal to actuator, actuator rotate valve through linkage and exhaust gases is manipulated.

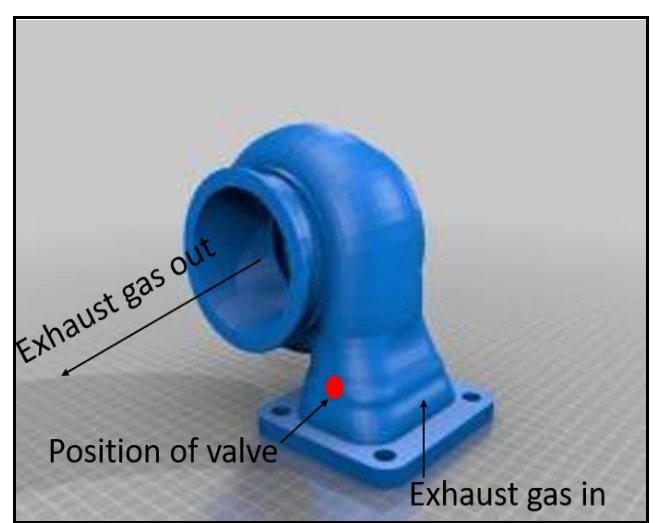

Fig. 1.1 Position of RTC valve in turbine housing [15]

General principle of RTC valve is as shown in fig. 1.2. RTC valve controls exhaust gases going in the turbine of turbocharger. Using RTC valve some amount of gas is sent to turbine wheel and some exhaust gas passes straight to the after-treatment system depending on the engine condition. RTC is one of the important inventions in automobile industry that can bypass $100 \%$ exhaust gas passes straight to the after-treatment system.

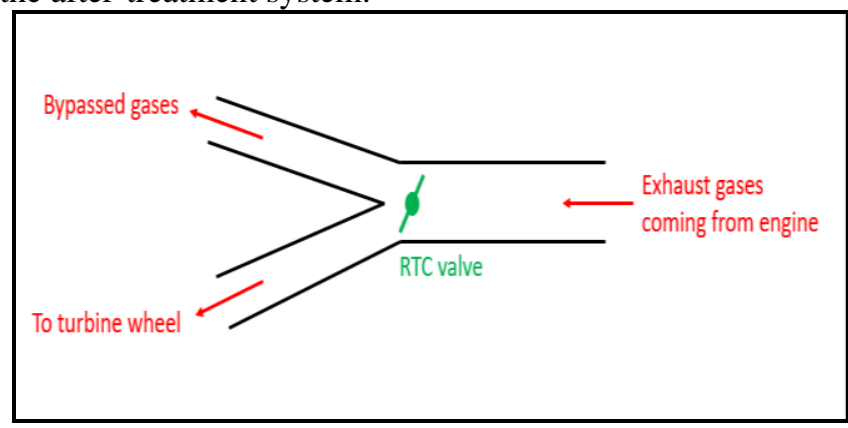

Fig. 1.2 RTC valve principal

Functions of RTC system:

1. Engine braking

2. Waste gating

3. Turbocharging

4. High volume bypass

\section{PROBLEM STATEMENT}

It contain two part and they are

1. Design of bracket for the actuator:

Actuator is driver of the RTC system is shown in figure 2.1. So, design bracket to support actuator on the turbine housing and validate design.

2. Design of heat shield for actuator and coil spring 
The RTC system is close to turbine housing (blue colour body in fig 2.1) and engine so it will exposed to high temperature. High temperature affects the working of actuator and spring so, design the heat shield for both and validate design.. Heat coming to spring and actuator is shown in fig. 2.1.

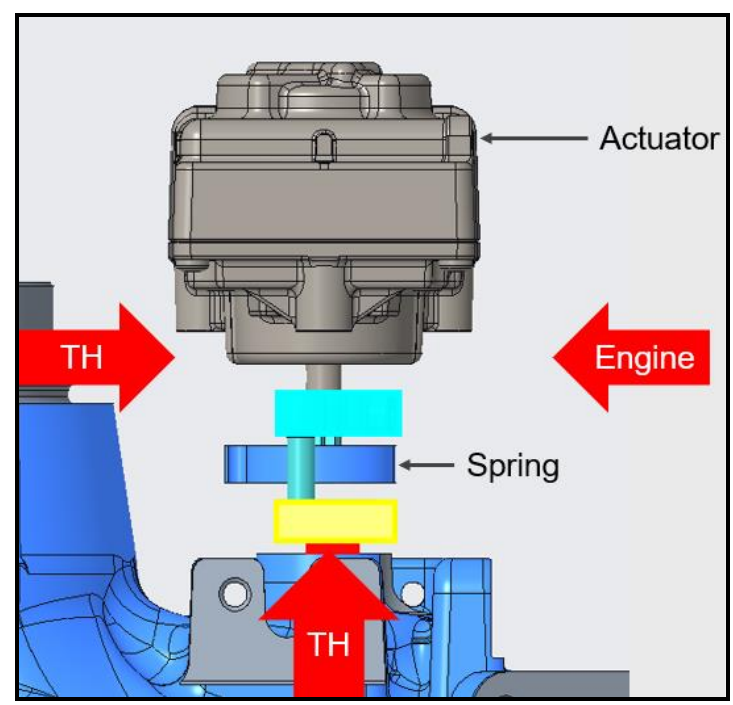

Figure 2.1 Heat coming to Actuator and Spring

\section{CONCEPT GENERATION FOR BRACKET AND HEAT SHIELD}

While designing bracket and bracket of heat shield of actuator and heat shield of spring various factors are considered and these are given space claim, material, cost and surrounding temperature. Few concepts for bracket and both heat shield are explained below:

\section{A. Concept A:}

In this concept, the designed bracket can be manufactured from one blank. The lower part of bracket is act as support of actuator and side wall of bracket act as heat shield for actuator and spring. For mounting of bracket on TH, 5 bolts are used. In fig. 3.1, orange part is a bracket this is manufactured from bending process.

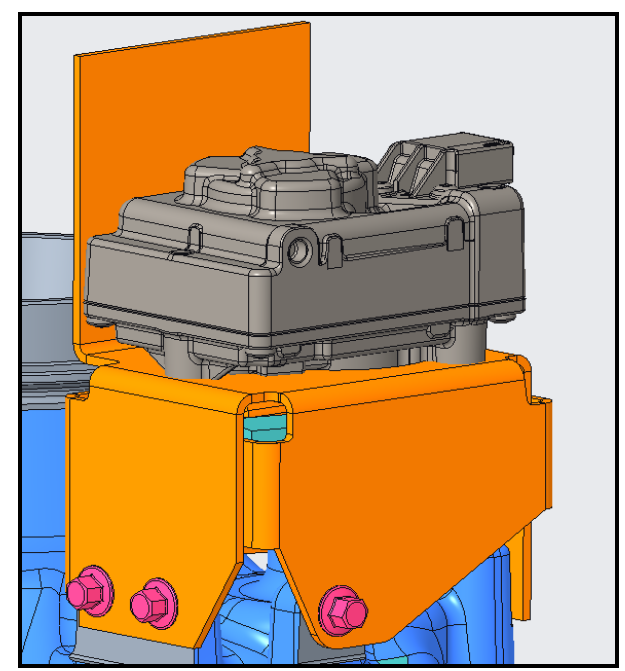

Fig. 3.1 Concept A
To protect actuator, actuator should be shield from 3 sides but in this concept the heat shield is for only one side of actuator this is the drawback of concept A.

\section{B. Concept B:}

In this concept, the separate heat shield is designed for actuator and spring and bracket for mounting of actuator. Bending process is used for manufacturing of heat shield and bracket. Both bracket and heat shield are mounted on the TH. In fig. 3.2 grey part is heat shield and orange part is bracket.

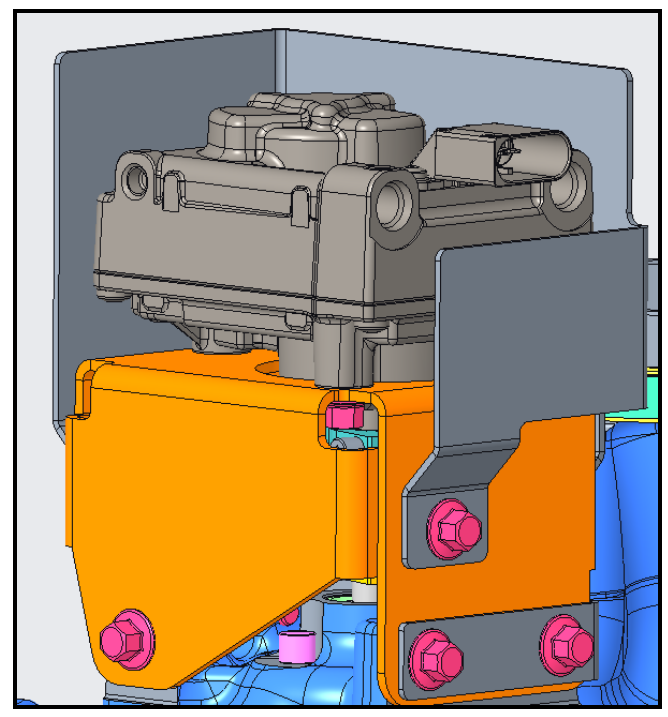

Fig. 3.2 Concept B

Drawback of concept B is that spring is still exposed to the radiation coming from inlet flange of $\mathrm{TH}$ shown by arrows in fig. 3.3.

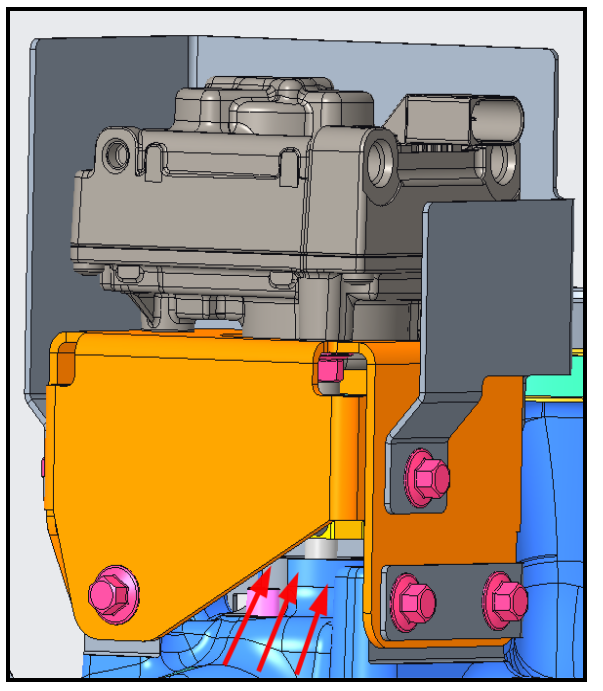

Fig. 3.3 Radiation coming to spring

\section{Concept C:}

This concept is addition to concept $\mathrm{B}$, the extra heat shield for spring is designed. In fig. 3.4 pink part is heat shield of spring. 


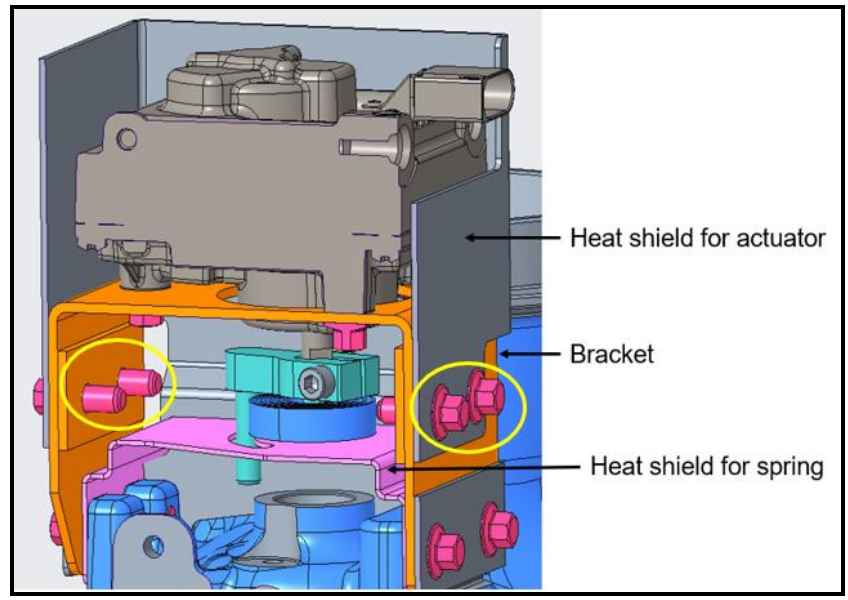

Fig. 3.4 Concept C

In this concept for mounting of heat shield of actuator 4 extra bolts are used shown in fig. 3.4 by circles which will increase cost this is the drawback.

\section{Concept D:}

The disadvantage of concept $\mathrm{C}$ is removed in this concept i.e. extra bolts are used for mounting of heat shield are removed. Concept is shown in fig. 3.5

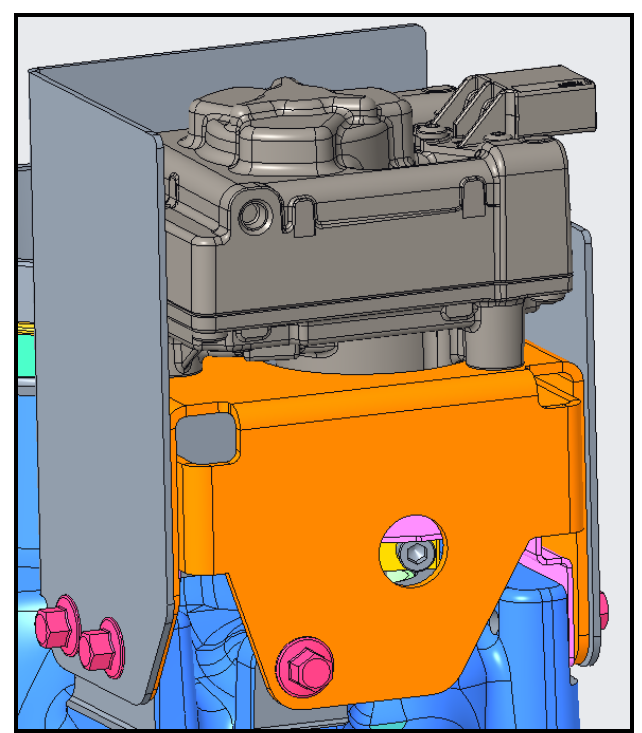

Fig. 3.5 Concept D

\section{CONCEPT SELECTION}

Concept selection is the process of evaluation concepts, comparing the relative strengths and weaknesses of the concepts and selecting one concept. The concept is finalized by considering factors like space claim, protection of all components of system, cost and different criteria. Pugh matrix and $\mathrm{CnE}$ matrix are used concept finalization.

\section{A. Pugh matrix:}

During concept selection, initially concepts are evaluated relative to a baseline product using the Pugh matrix. Pugh matrix compares all concepts with baseline and gives best concept from all. For Pugh matrix used for the concept selection refer Table 1 in Appendix.
After the rating in Pugh matrix, concept $\mathrm{C}$ and concept $\mathrm{D}$ got same rank. To select best concept from these $2 \mathrm{CnE}$ matrix is used.

\section{B. CnE matrix:}

In this matrix, ratings from 1 to 10 are given for the concepts. One more advantage of this matrix is weightage is also given to the criterions, so we can get more accurate result. In a $\mathrm{C} \& \mathrm{E}$ matrix, customer requirements i.e. criteria are ranked by order of importance to the customer. The $\mathrm{CnE}$ matrix is shown in Table 2 in appendix. The meaning of rating used for comparing concept with baseline is;

0- None, 1- Weak, 3- Moderate, 9- Strong

As the Concept $\mathrm{D}$ got high rating in $\mathrm{CnE}$ matrix sheet so this concept is finalized.

\section{DESIGN OF SELECTED CONCEPT}

While designing final concept in details following factors are considered:

1. Available space claim

2. Material of bracket and heat shield as per surrounding temperature

3. Overhang reduction of RTC linkage

\section{A. Design of bracket:}

The actuator having $1 \mathrm{Kg}$ mass is mounted on bracket and bracket is fixed on TH using 5 bolts. As grade 304 stainless steel have high tensile strength so this material is selected for it. As bracket manufactured by bending procedure so its thickness decided as $3 \mathrm{~mm}$. (as thickness of $3 \mathrm{~mm}$ of sheet is widely preferred in Cummins and for manufacturing of sheet having thickness greater than $3 \mathrm{~mm}$, special tools are required which require more cost). The detailed view of bracket is as shown in figure 5.1 .

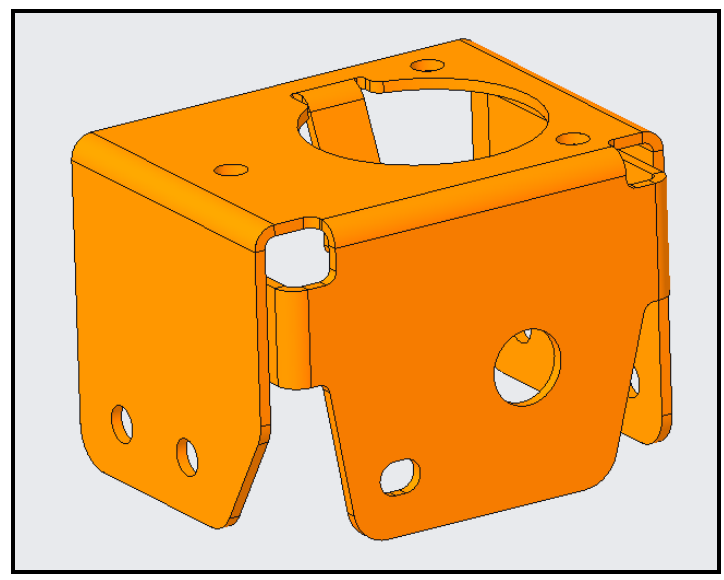

Fig. 5.1 Bracket

\section{B. Design of heat shield of actuator}

By considering space between turbine housing and actuator, the thickness of this heat shield is selected as $2 \mathrm{~mm}$. The material for heat shield is selected as grade 304 stainless steel because it have good thermal resistance and high melting point. The detailed view of heat shield for actuator is as shown in figure 5.2 . 


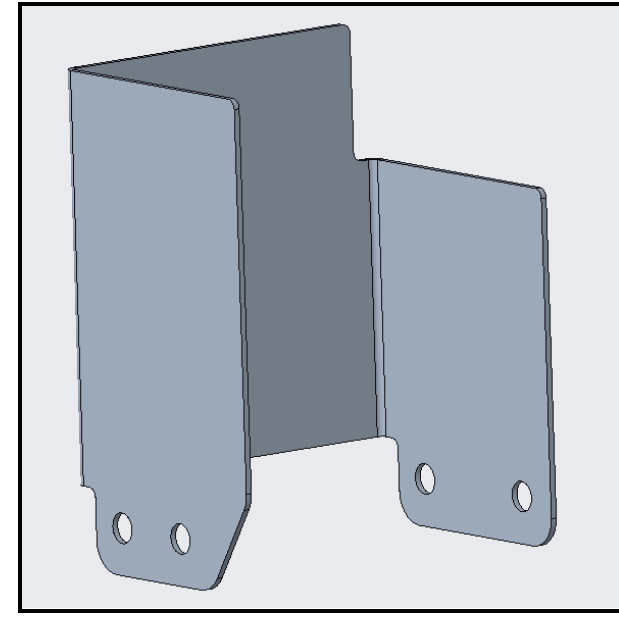

Figure 5.2 Final heat shield for actuator view

\section{Design of heat shield of spring:}

By considering gap between spring and valve side lever arm of RTC linkage the thickness of this heat shield is selected as $1.5 \mathrm{~mm}$. The material for heat shield is selected as grade 304 stainless steel. The detailed view of heat shield for spring is as shown in figure 5.3.

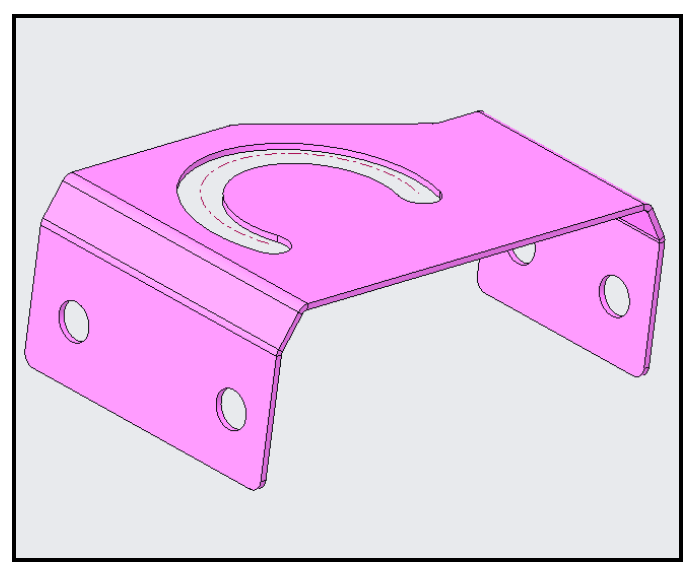

Figure 5.3 Final view of heat shield for spring

\section{VALIDATION OF DESIGN}

The modal analysis and RVA are performed to check the strength of bracket. Steady thermal analysis is performed to calculate temperature of actuator and spring before and after mounting of heat shield.

\section{Modal Analysis}

Modal analysis examines the modal behavior of model. Modal analysis is used to calculate the natural frequencies and mode shapes of model.

The analytical frequency of bracket and heat shield for inline engine is given by below equation.

Engine speed- $3000 \mathrm{rpm}$

Number of cylinders of engine- 6

$=\underline{\text { (maximum speed of engine }+10 \% \text { of maximum speed } X \text { mumber of cylinder }}$ 60

$=330 \mathrm{~Hz}$

\subsubsection{Geometry details:}

The assembly of following parts is considered for modal analysis as shown in fig. 6.1.

1. Heat shield for spring

2. Bracket

3. Heat shield for actuator

4. Actuator

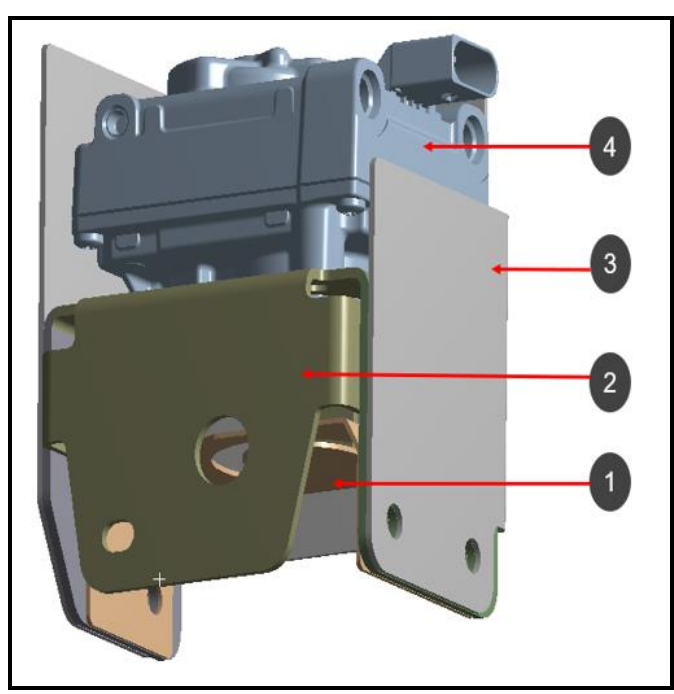

Figure 6.1 Geometry details for modal analysis

The mass of actuator is 1 kilogram. This mass is acting at CG (Centre of Gravity) of actuator assembly.

\subsubsection{Material properties:}

The material properties for all components are as shown in table 3 .

Table 3 Material properties of all components

\begin{tabular}{|c|c|c|c|c|}
\hline 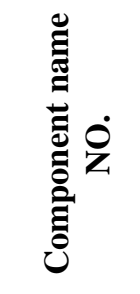 & 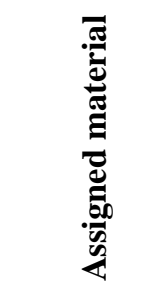 & 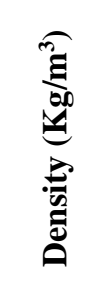 & 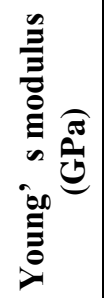 & 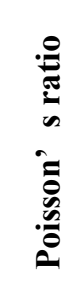 \\
\hline $1,2,3$ & AISI 304 & 7858 & 193 & 0.28 \\
\hline Actuator & $\begin{array}{c}\text { Sonceboz } \\
\text { Watercool }\end{array}$ & 2250 & 71 & 0.3 \\
\hline
\end{tabular}

\subsubsection{Coordinate system:}

In this case, global coordinate system is used as coordinate system.

\subsubsection{Contact details:}

In this case, for all contact bonded contact is selected. 


\subsubsection{Mesh details:}

Mesh generation is the practice of creating a mesh, a subdivision of a continuous geometric space into discrete geometric and topological cells.

The element size of all components is as shown in table 4.

Table 4 Element details of all components

\begin{tabular}{|l|l|c|}
\hline Sr. No. & Component name & Element size (mm) \\
\hline 1 & Heat shield for spring & 4 \\
\hline 2 & Bracket & 4 \\
\hline 3 & Heat shield for Actuator & 4 \\
\hline 4 & Actuator & 3 \\
\hline 5 & Face sizing at all contacts & 2 \\
\hline
\end{tabular}

The body sizing of various components is as shown in fig. 6.2 .

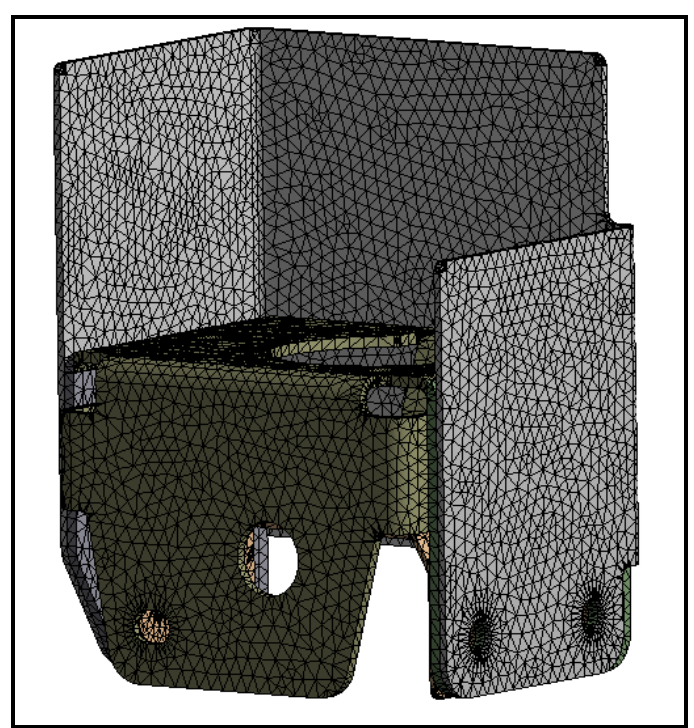

Fig.6.2 Mesh details

\subsubsection{Boundary condition:}

For modal analysis, the fixed support is given to bracket where all parts are going to be fixed on turbine housing. The fixed support is given to the highlighted areas shown by blue color as shown in fig 6.3 and in fig 6.4.

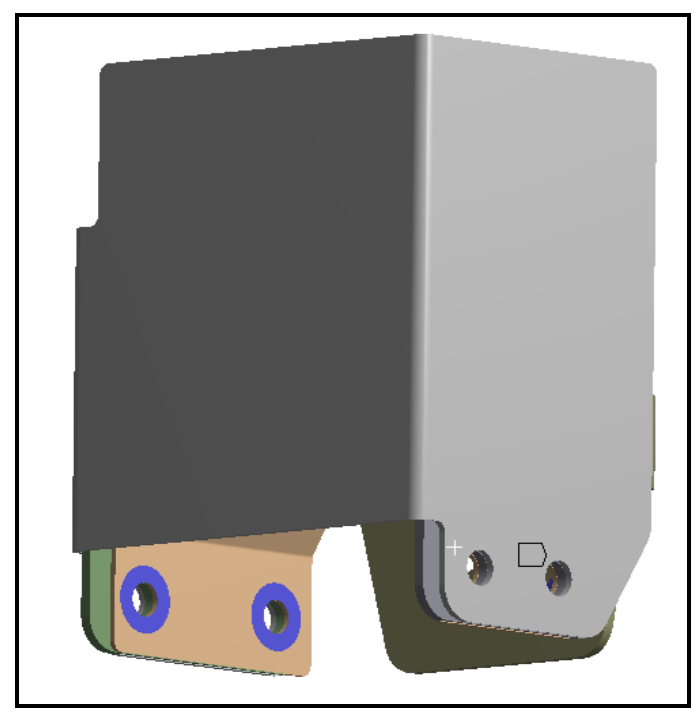

Fig. 6.3 Boundary condition- Part 1

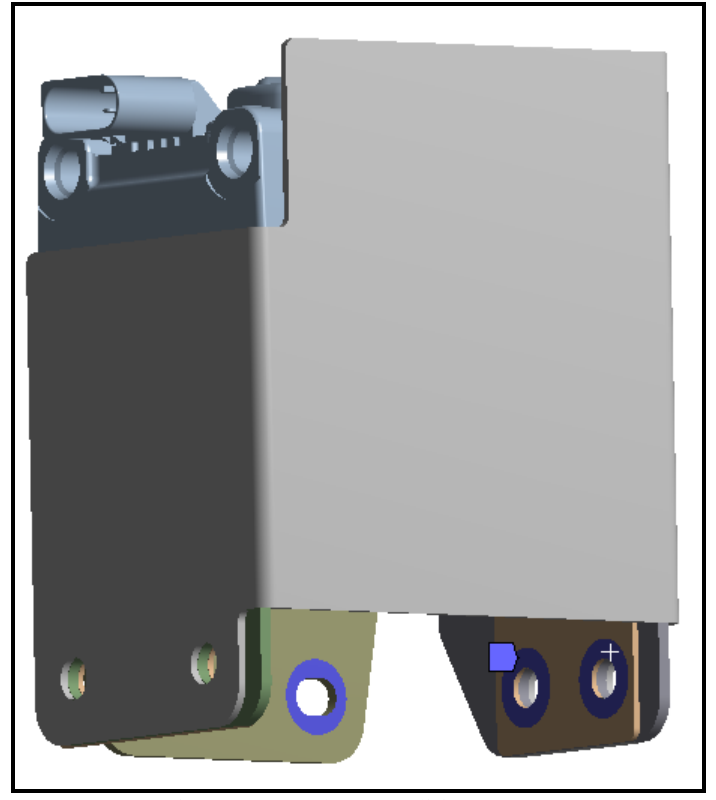

Fig. 6.4 Boundary condition- part 2

\subsubsection{Various modes of modal analysis}

In modal analysis 4 modes are considered. The various modes and respective frequency are shown in next few pages. The turbine housing and actuator are hidden while taking snap on modes as it is confidential.

\section{Mode 1}

Frequency achieved in mode 1 is $356.28 \mathrm{~Hz}$.

The displacement is dominant in Y-direction as shown in fig. 6.5 In this mode shape, heat shield of actuator goes under maximum displacement.

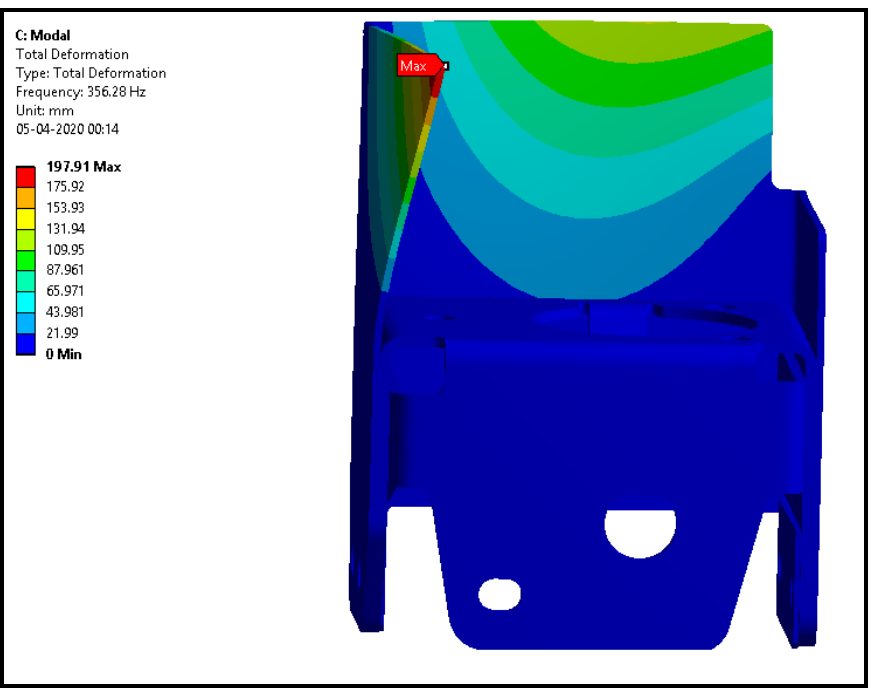

Fig. 6.5 Mode shape of mode 1

\section{Mode 2}

Frequency achieved of this mode is $457.15 \mathrm{~Hz}$.

In this mode, the displacement of heat shield of actuator is maximum and it is dominant in $\mathrm{Y}$-direction as shown in fig. 6.6. 


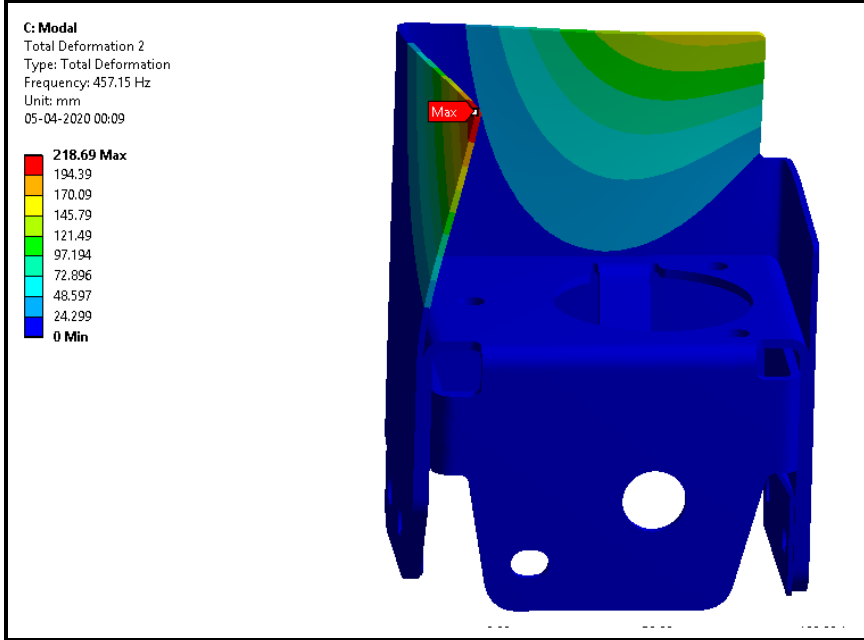

Fig. 6.6 Mode shape of mode 2

\section{3. $\quad$ Mode 3}

Frequency achieved of this mode is $488.1 \mathrm{~Hz}$.

The displacement is dominant in X-direction as shown in fig. 6.7. In this mode shape, the maximum deformation occurs in the heat shield of spring.

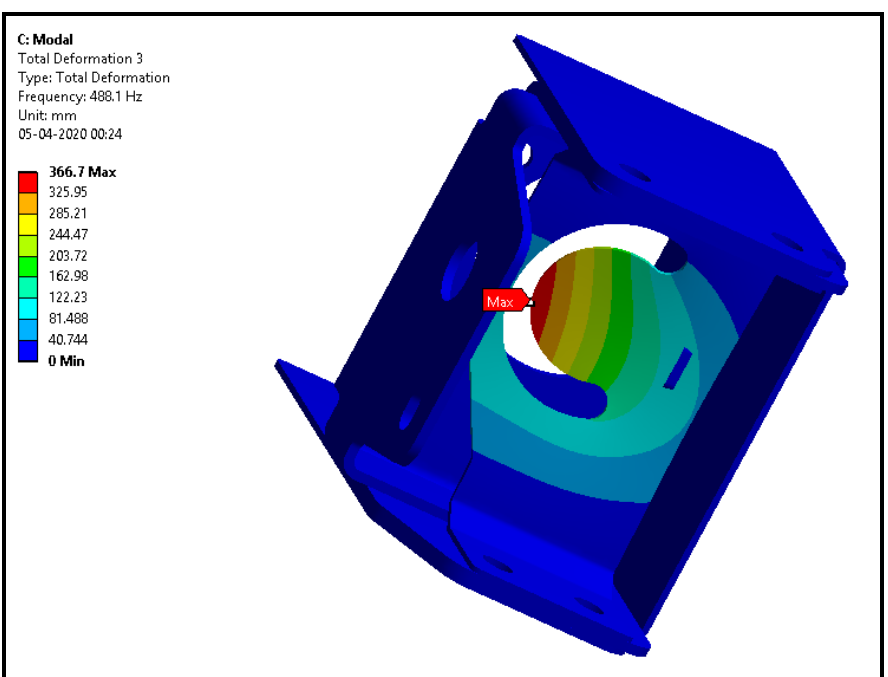

Fig. 6.7 Mode shape of mode 3

\section{Mode 4}

Frequency achieved of mode 4 is $592.65 \mathrm{~Hz}$.

In this mode shape there, deformation of bracket in $\mathrm{X}$ direction and heat shield of actuator in Z-direction occurred but deformation of bracket is maximum. The maximum displacement is dominant in $\mathrm{X}$-direction as shown in fig. 6.8.

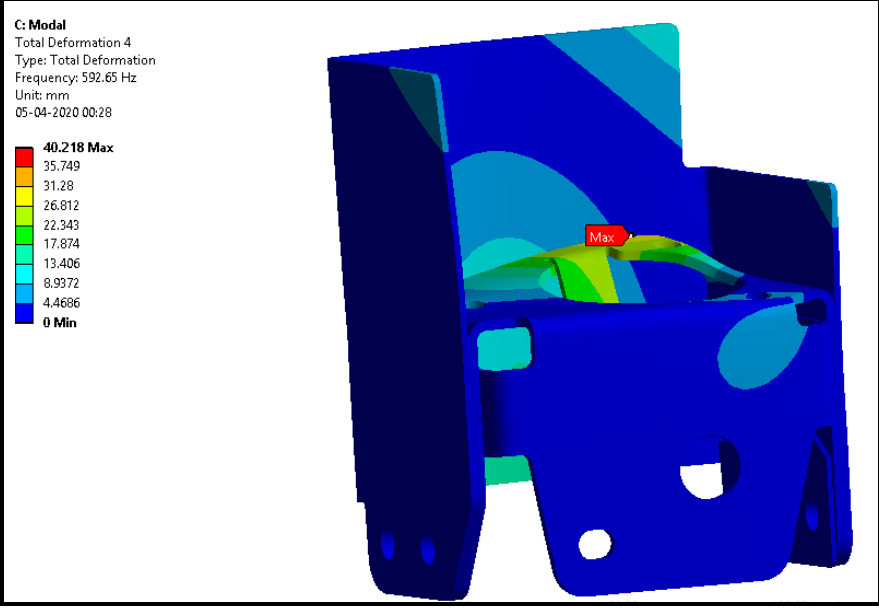

Fig. 6.8 Mode shape of mode 4

Conclusion:

The graph of natural frequency is shown in graph 1

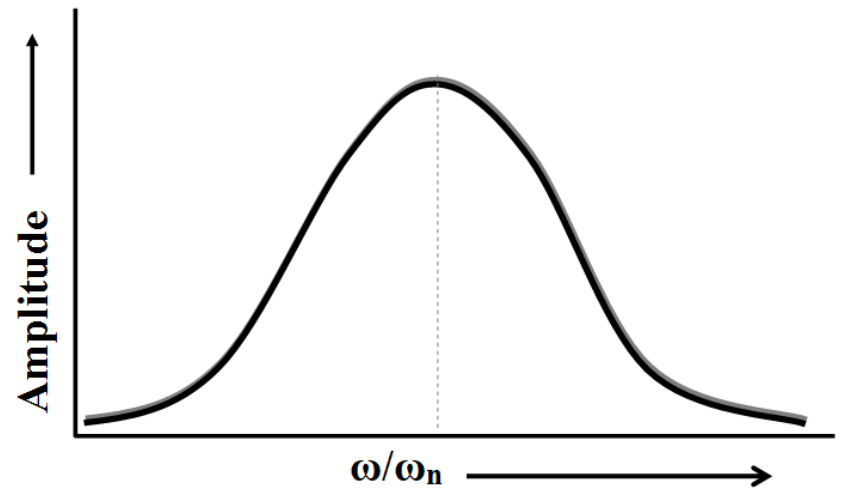

Where,

On X-axis $\omega / \omega_{\mathrm{n}}$ is plotted, where $\omega$ is applied frequency and $\omega_{\mathrm{n}}$ is natural frequency and on Y-Axis is Amplitude plotted.

When $\omega / \omega_{\mathrm{n}}$ is equal to 1 i.e. applied frequency is equal to natural frequency of the system resonance occurs and system vibrates very harshly which may cause failure of it.

In order to ensure safe working of the system, the ratio $\omega / \omega_{n}$ should be either below or above one, i.e. experimental natural frequency should be much below or above the resonant condition.

In this case applied frequency is $330 \mathrm{~Hz}$ while that obtained from Ansys is $350 \mathrm{~Hz}$, thus ratio of $\omega / \omega_{\mathrm{n}}>1$ and system is safe.

When natural frequency from Ansys is less than calculated frequency then also system is safe, but if there are any changes in operating conditions it is possible that natural frequency may increase and reach resonant condition which is not desirable.

Therefore, it is safe to say that natural frequency from Ansys which emulates real world condition during loading and boundary condition must be greater than analytical frequency to ensure safety of the system. Thus, bracket design is safe.

\section{Random Vibration Analysis:}

A random vibration analysis provides the likely structural response to a spectrum of random excitations. Random vibration can be represented in the frequency domain by a PSD function. PSD is graph where acceleration $\left[\mathrm{G}^{\wedge} 2 / \mathrm{Hz}\right]$ 
versus frequency $[\mathrm{Hz}]$ are plotted. To get PSD data, road condition applied to engine and run the engine, the acceleration versus frequency data is plotted.

\subsection{Boundary condition:}

The PSD-G data is taken from the test cell. This PSD data is applied at fixed support shown fig. 6.4 and fig. 6.5.

\subsection{Results:}

The equivalent stress is calculated in RVA analysis. This stress is calculated in 3 direction i.e. X-direction, $\mathrm{Y}$-direction and Z-direction.

a. Equivalent stress generated in $X$-direction:

The maximum stress is generated in bracket and it is 61.28 MPa is shown in fig. 6.9.

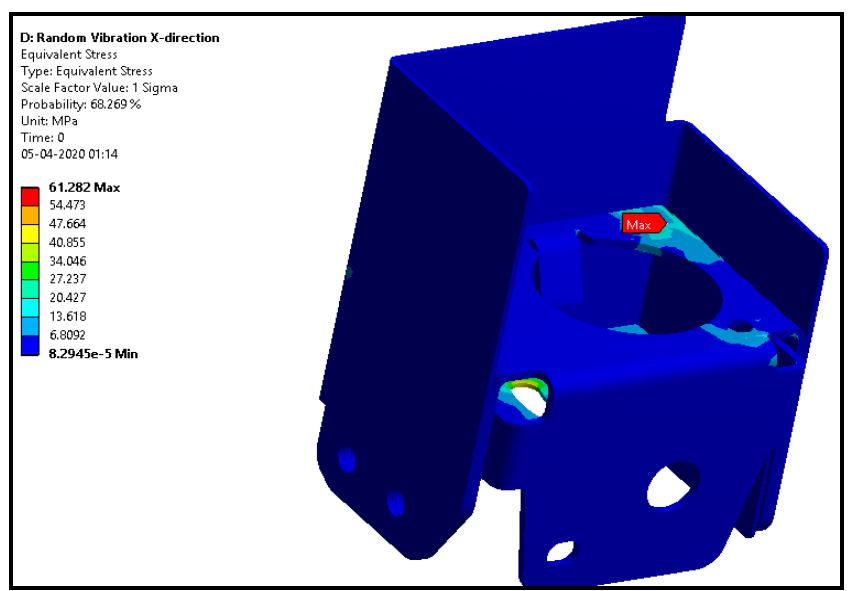

Fig. 6.9 Equivalent stress generated in X-direction

b. Equivalent stress generated in $Y$-direction:

The maximum stress is occurred in heat shield of actuator and is $79.4 \mathrm{MPa}$ is shown in fig. 6.10 .

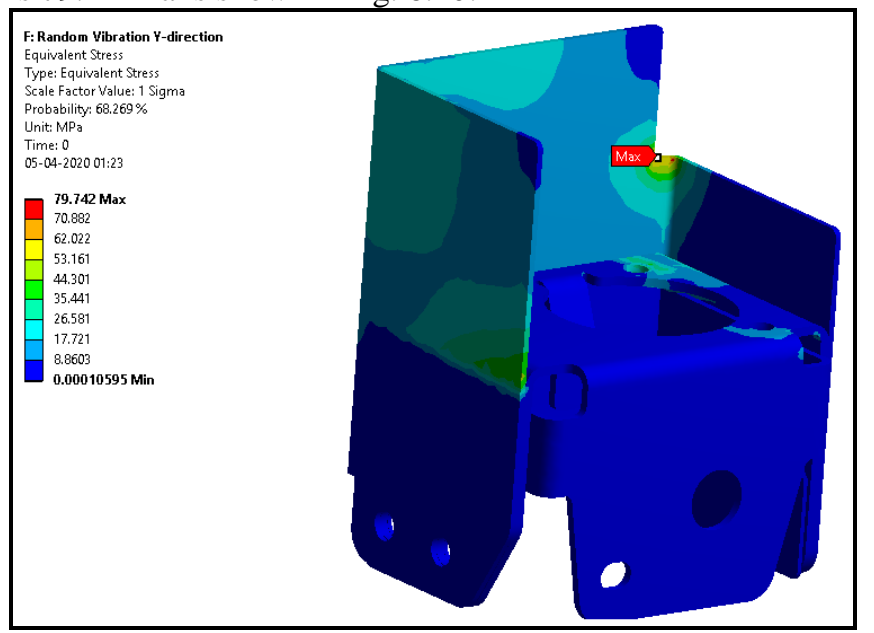

Fig. 6.10 Equivalent stress generated in Y-direction

\section{c. Equivalent stress generated in Z-direction:}

The maximum stress generated is $101.94 \mathrm{MPa}$ is shown in fig. 6.11.

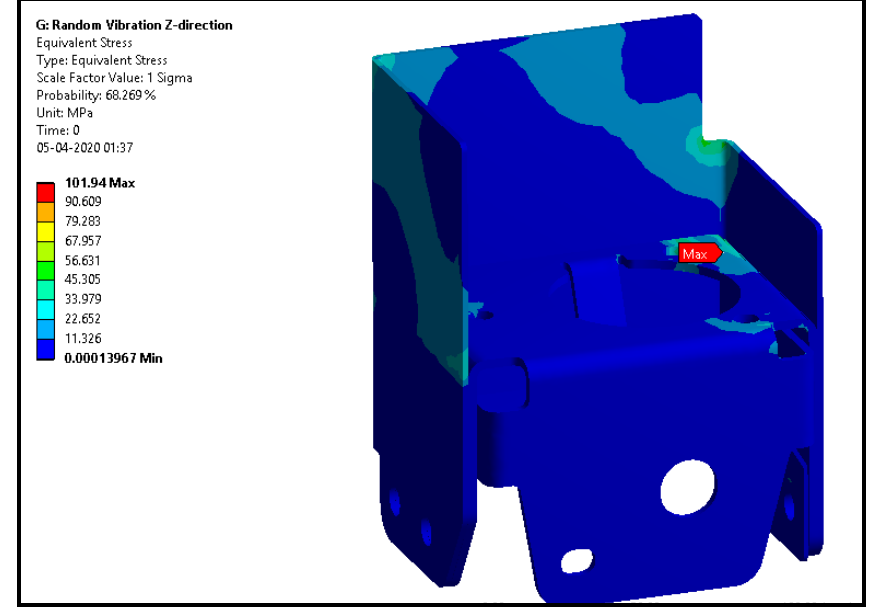

Fig. 6.11 Equivalent stress generated in Z-direction

Conclusion:

Analysis of Random Vibration response of the model finite element was conducted on the basis of modal analysis. From the above result, it is clear that maximum stress is generated at bend of bracket and heat shield of actuator. These stresses are generated because of sharp edges. In actual practice, there should not be any sharp edge at bend so, no stress generated in bracket and heat shield. So, this design is safe.

\section{Thermal analysis:}

The steady-state thermal analysis is used to calculate the thermal response of system to heat loads depending on the applied thermal conditions. Steady-state thermal analysis assumes a steady-state for all thermal loads and boundary conditions. Steady state means thermal loads are not varying with the time.

3.1 Geometry details:

The assembly of following parts is considered for this analysis as shown in fig. 6.12.

1. Turbine housing

2. RTC valve

3. Valve side lever arm

4. Heat shield for spring

5. Actuator side lever arm

6. Bracket

7. Actuator

8. Heat shield for actuator

Spring will fit on the extrusion of part number 5 i.e. actuator side lever arm. Temperature of spring will be same as the temperature of extrusion of part number 5 so, spring is not taken in analysis. This is for convenience. 


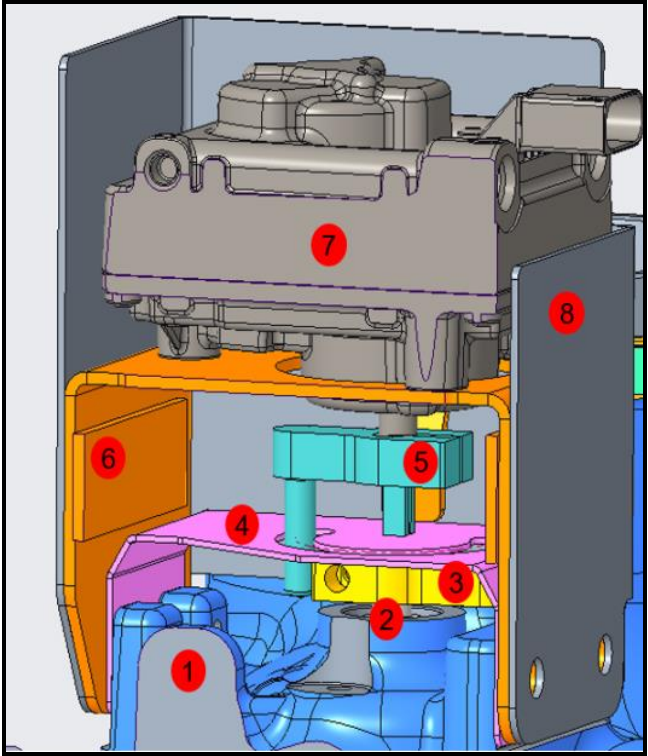

Fig. 6.12 Geometry details for modal analysis

\subsection{Material properties:}

The material properties for all components are as shown in table 5 .

Table 5 Material properties of all components

\begin{tabular}{|c|c|c|c|c|}
\hline 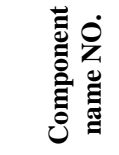 & 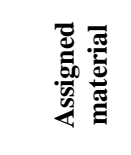 & 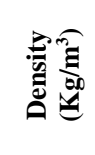 & 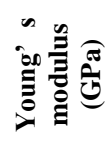 & 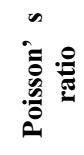 \\
\hline 1 & S.G.Iron & 6980 & 163 & 0.29 \\
\hline 2 & AISI 431 & 7800 & 200 & 0.3 \\
\hline $3,4,5,6,8$ & AISI 304 & 7858 & 193 & 0.28 \\
\hline 7 & $\begin{array}{l}\text { Sonceboz- } \\
\text { Watercool }\end{array}$ & 2250 & 71 & 0.3 \\
\hline
\end{tabular}

\subsection{Coordinate system:}

In this case, global coordinate system is used as coordinate system.

\subsection{Contact details:}

In this case, for all contact bonded contact is selected.

\subsection{Mesh details:}

Element size of all elements used for meshing are listed in table 6.

Table 6 Element details of all components

\begin{tabular}{|c|l|c|}
\hline Sr. No. & Component name & Element size (mm) \\
\hline 1 & Turbine housing & 4 \\
\hline 2 & Valve & 3 \\
\hline 3 & Valve side lever arm & 3 \\
\hline 4 & Heat shield for spring & 3 \\
\hline 5 & Actuator side lever arm & 3 \\
\hline 6 & Bracket & 3 \\
\hline 7 & Actuator & 3 \\
\hline 8 & Heat shield for actuator & 4 \\
\hline 9 & For all face contact & \\
\hline
\end{tabular}

The meshing is shown in fig. 6.13.

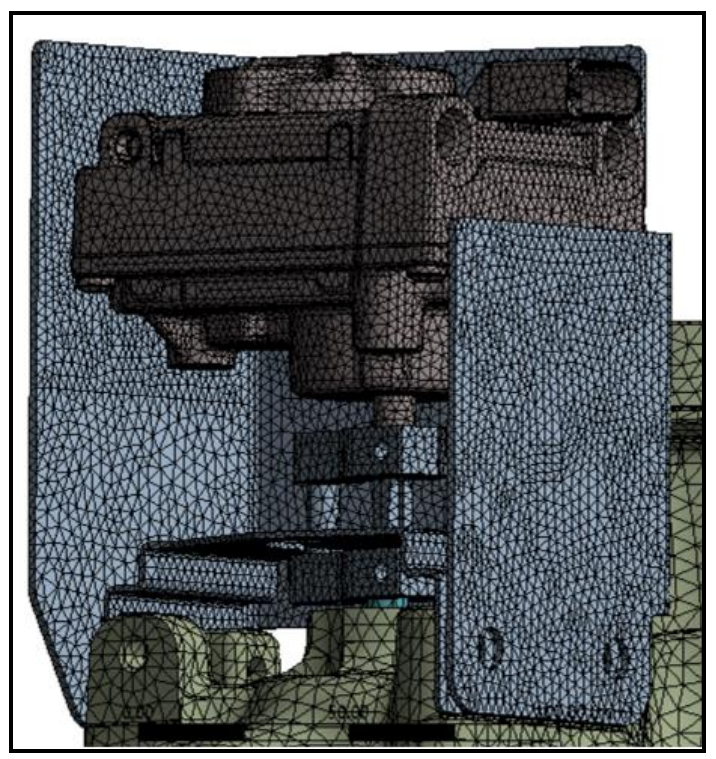

Fig. 6.13 Mesh details

\subsection{Boundary condition:}

The heat from TH and engine is transferred to RTC system components by 3 modes i.e. conduction, convection and radiation. But radiation mode is dominant over other mode so radiation mode is considered for this analysis. For the radiation following are the boundary conditions.

\section{First condition for actuator-}

Emitter source- The radiated surface of turbine housing is shown by blue colored surface as shown in fig. 6.14. The temperature of surface is $77^{\circ} \mathrm{C}$ and emissivity factor is 0.94 .

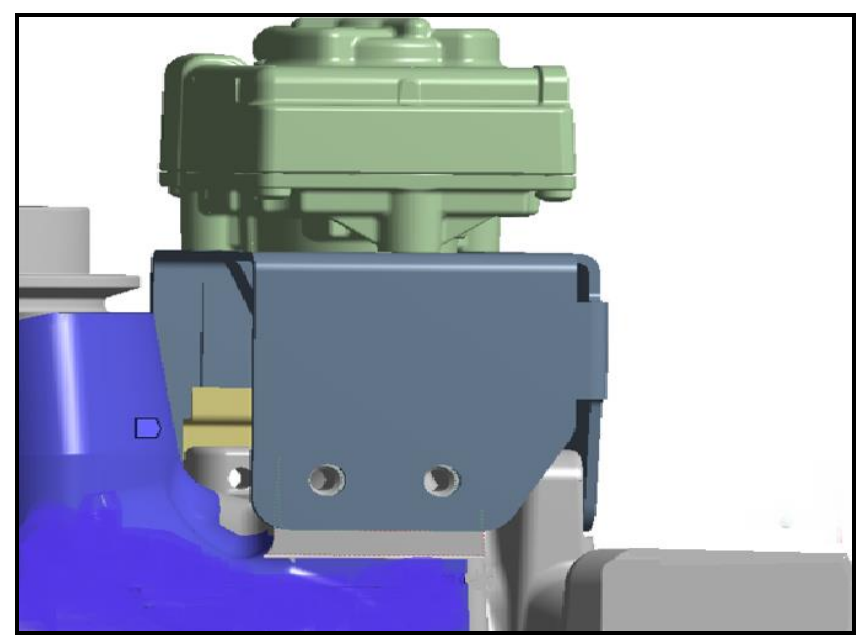

Fig. 6.14 Emitter surface of turbine housing

Receiver source without heat shield- The receiver surface is actuator is shown by blue colored surface as shown in fig 6.15. The temperature of surface is $77^{\circ} \mathrm{C}$ and emissivity factor is 0.8 . 


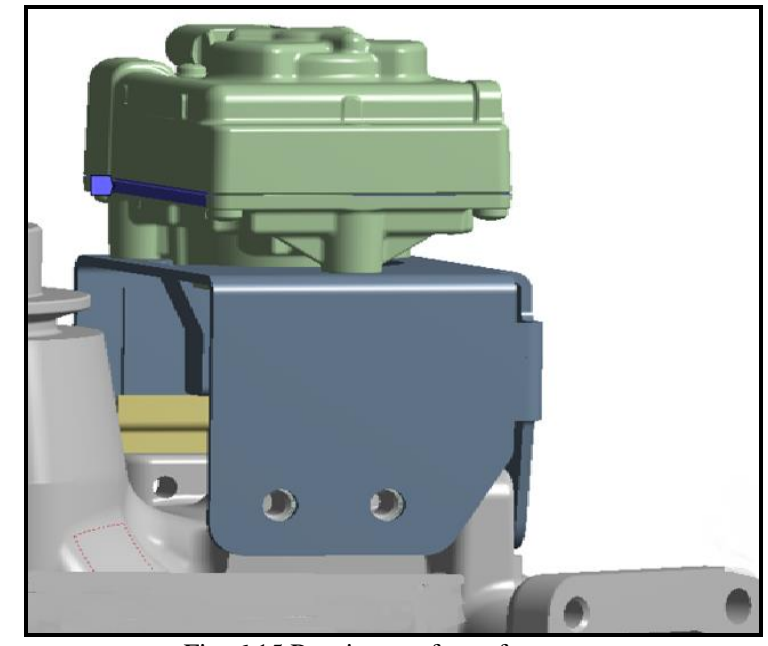

Fig. 6.15 Receiver surface of actuator

Receiver source with heat shield- The receiver surface is heat shield for actuator is shown by blue colored surface as shown in fig 6.16. The temperature of surface is $77^{\circ} \mathrm{C}$ and emissivity factor is 0.8 .

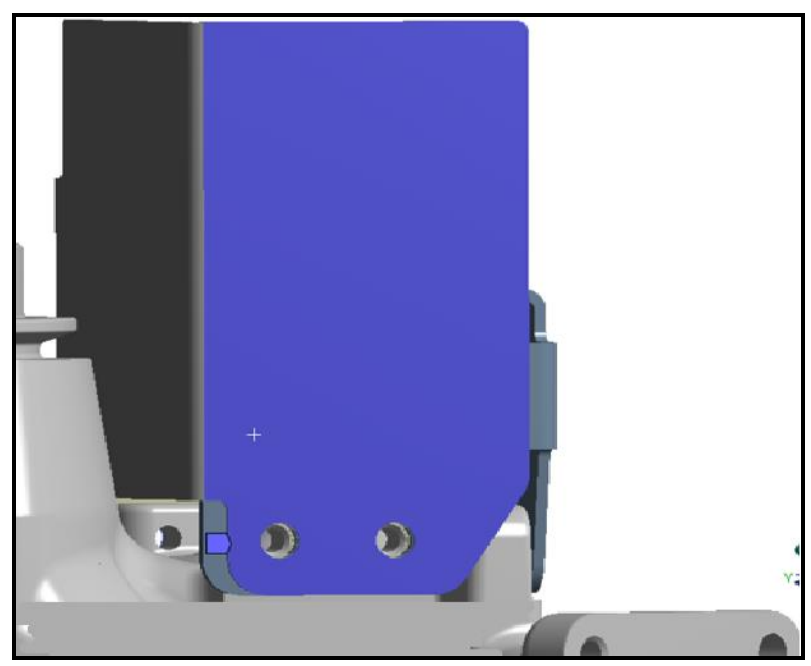

Fig.6.16 Receiver surface- heat shield of actuator

Second condition for actuator-

Emitter source- The high temperature exhaust gases in the outlet of turbine housing radiates lot of heat is shown by blue colored surface as shown in fig. 6.17. The temperature of surface is $675^{\circ} \mathrm{C}$ and emissivity factor is 0.94 .

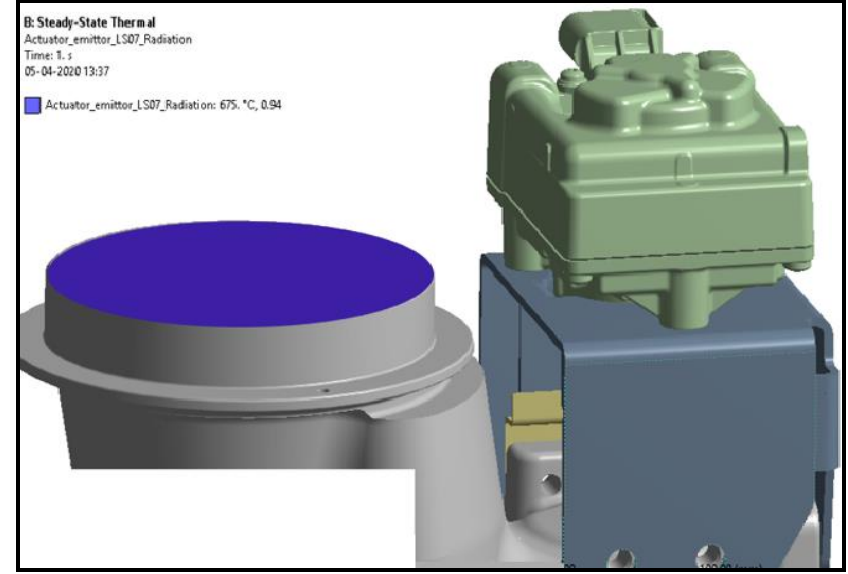

Fig. 6.17 Emitter surface of turbine housing

Receiver source without heat shield- The receiver surface is actuator is shown by blue colored surface as shown in fig.6.18. The temperature of surface is $675^{\circ} \mathrm{C}$ and emissivity factor is 0.8 .

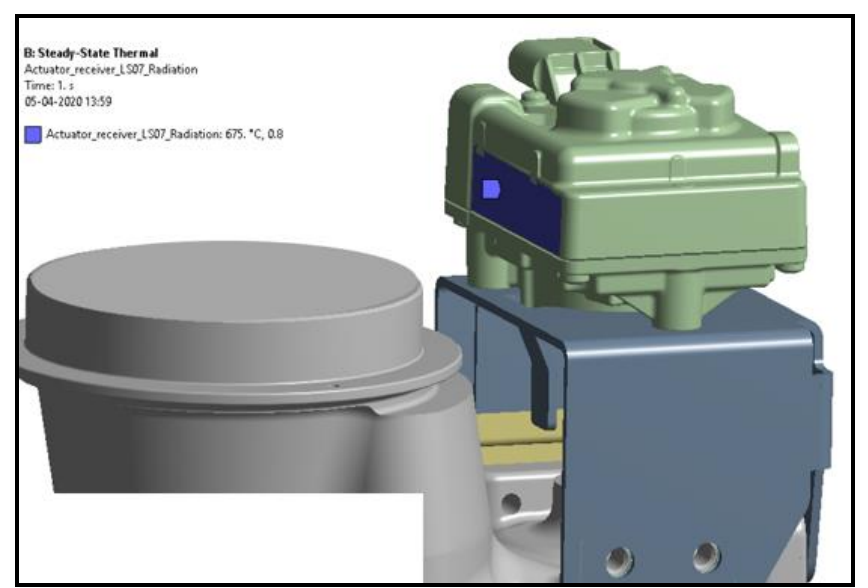

Fig. 6.18 Receiver surface of actuator

Receiver source with heat shield- The receiver surface is heat shield for actuator is shown by blue colored surface as shown in fig. 6.19. The temperature of surface is $675^{\circ} \mathrm{C}$ and emissivity factor is 0.8 .

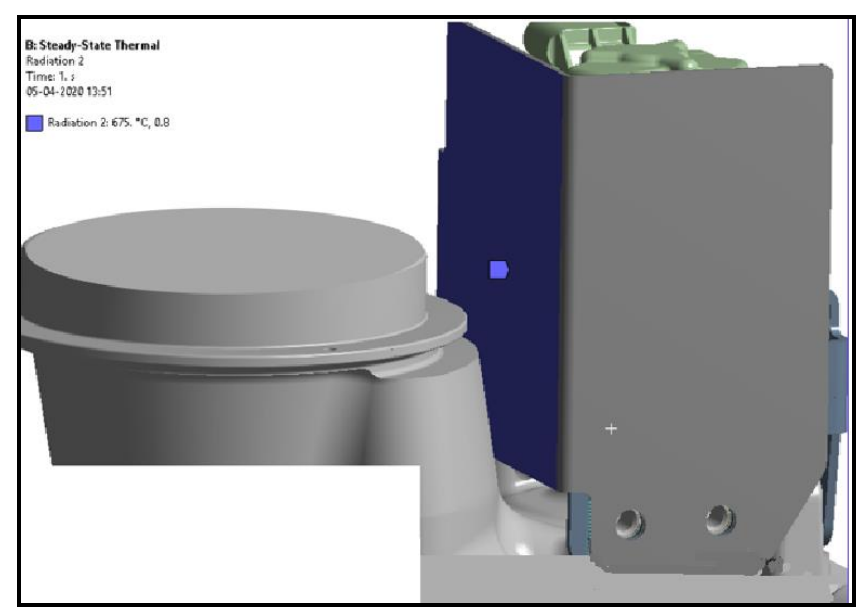

Fig.6.19 Receiver surface- heat shield of actuator 


\section{Third condition for spring-}

Emitter source- The radiated surface of turbine housing is shown by blue colored surface as shown in fig. 6.20. The temperature of surface is $77^{\circ} \mathrm{C}$ and emissivity factor is 0.94 .

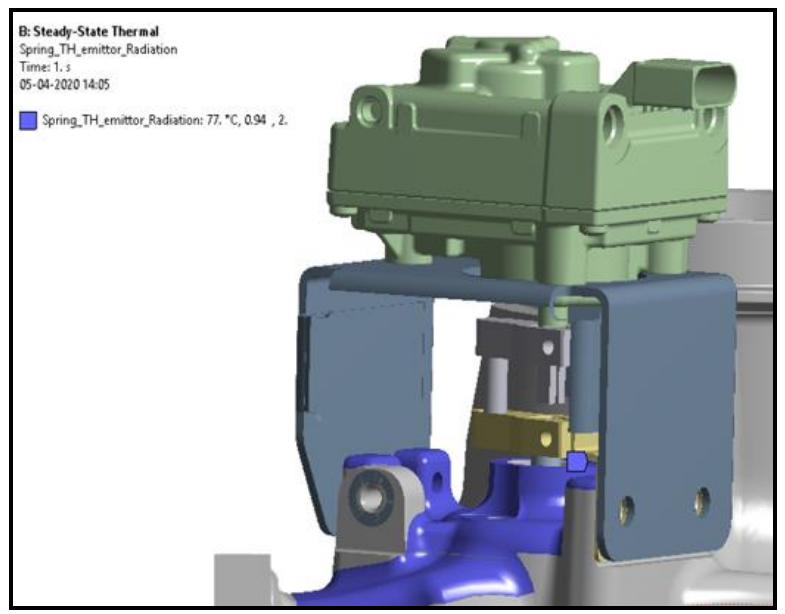

Fig. 6.20 Emitter surface of turbine housing

Receiver source without heat shield- The receiver surface is spring is shown by blue colored surface as shown in fig. 6.21 Here lower surface of actuator side lever arm is considered as receiver instead of spring surface. The temperature of surface is $77^{\circ} \mathrm{C}$ and emissivity factor is 0.8 .

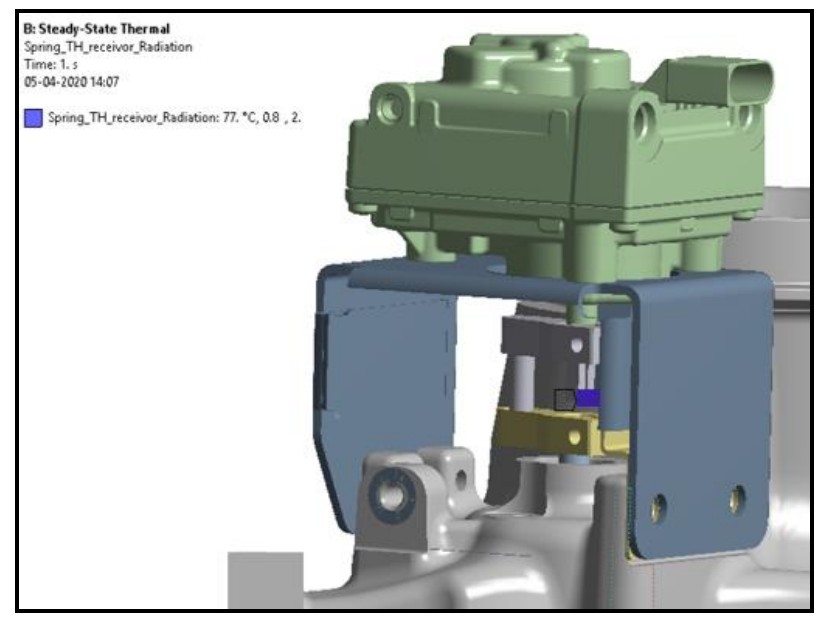

Fig. 6.21 Receiver surface of actuator

Receiver source with heat shield- The receiver surface is heat shield for spring is shown by blue colored surface as shown in fig. 6.22. The temperature of surface is $77^{\circ} \mathrm{C}$ and emissivity factor is 0.8 .

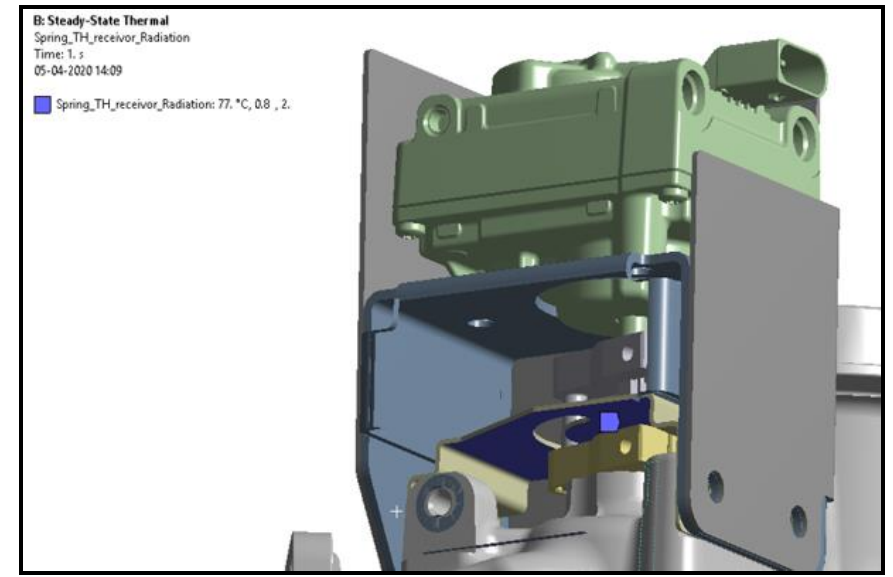

Fig. 6.22 Receiver surface- heat shield of spring

\section{Forth condition for spring-}

Emitter source- from the inlet of the turbine housing the high radiation are coming to the spring. The radiated surface of turbine housing is shown by blue colored surface as shown in fig. 6.23 . The temperature of surface is $700^{\circ} \mathrm{C}$ and emissivity factor is 0.94 .

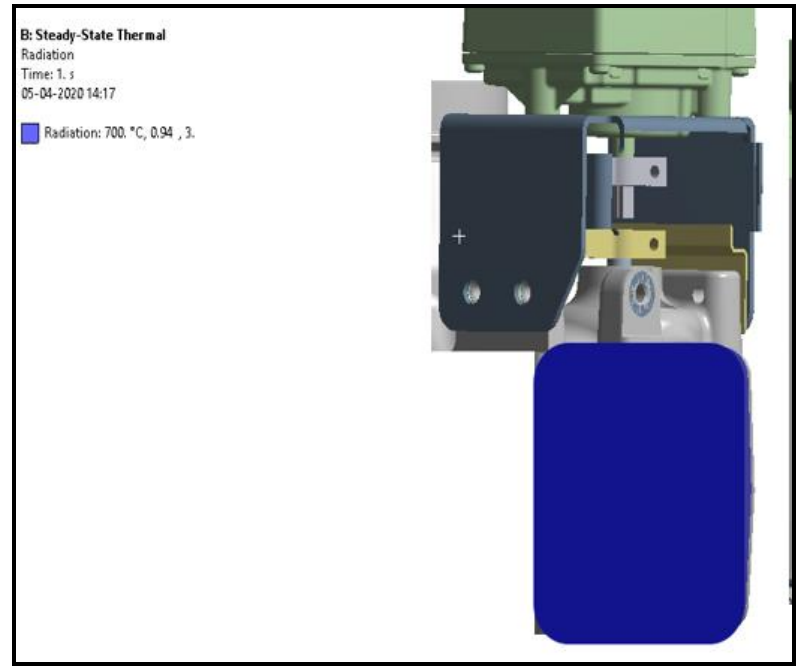

Fig. 6.23 Emitter surface of turbine housing

Receiver source without heat shield- The receiver surface is spring is shown by blue colored surface as shown in fig. 6.24. Here surface of actuator side lever arm is considered as receiver instead of spring surface. The temperature of surface is $700^{\circ} \mathrm{C}$ and emissivity factor is 0.8 . 


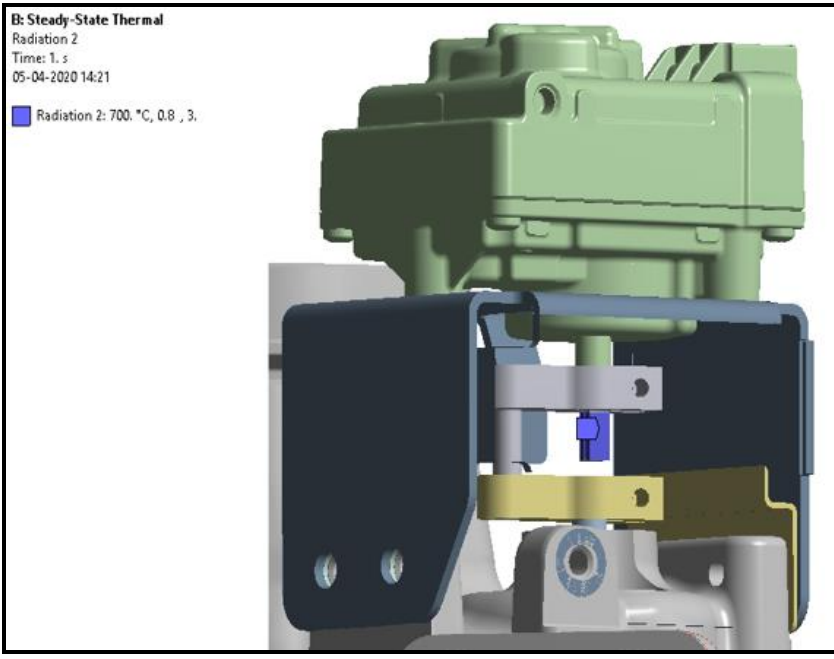

Fig. 6.24 Receiver surface of actuator

Receiver source with heat shield- The receiver surface is heat shield for spring is shown by blue colored surface as shown in fig. 6.25. The temperature of surface is $700^{\circ} \mathrm{C}$ and emissivity factor is 0.8 .

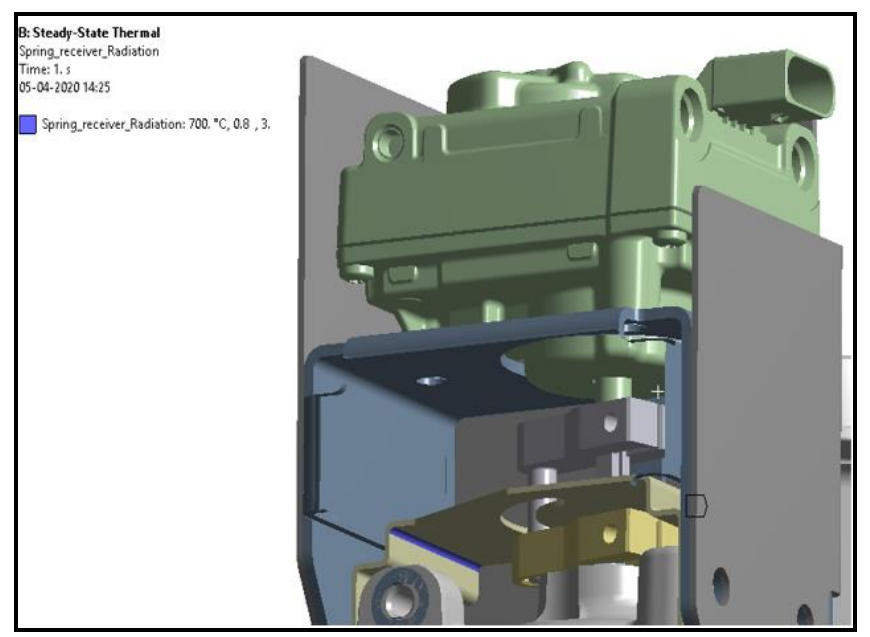

Fig. 6.25 Receiver surface- heat shield of spring

\subsection{Results:}

Temperature of actuator and spring are explained-

\section{a. Actuator:}

The temperature of actuator without heat shield is $106.13{ }^{\circ} \mathrm{C}$ as shown in fig. 6.26.

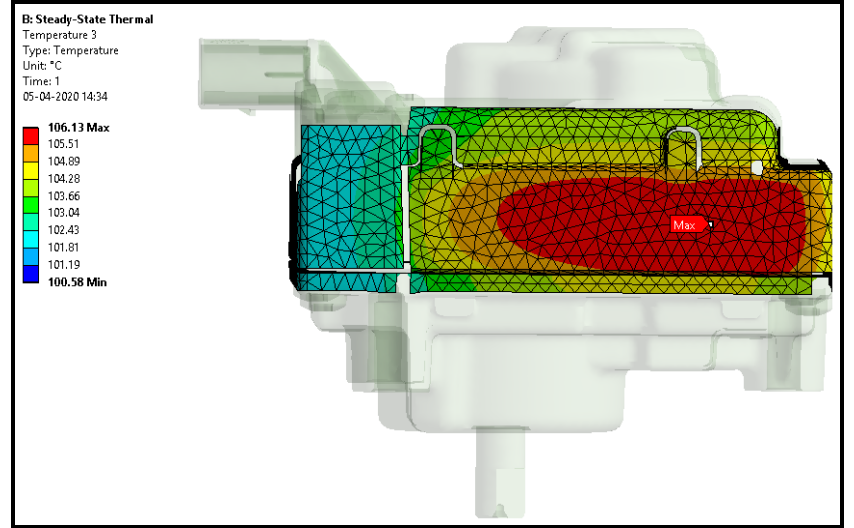

Fig. 6.26 Temperature of actuator without heat shield

Temperature of actuator with heat shield is $80.29{ }^{0} \mathrm{C}$ as shown in fig. 6.27.

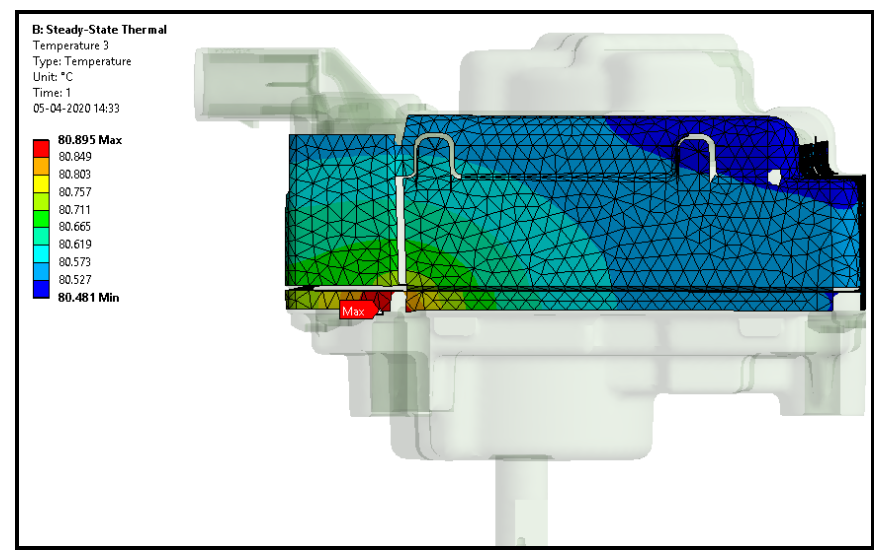

Fig. 6.27 Temperature of actuator with heat shield

The temperature of actuator is reduced by $26^{\circ} \mathrm{C}$ after the installation of heat shield for actuator.

\section{b. Spring:}

The temperature of spring without heat shield is $252.87{ }^{\circ} \mathrm{C}$ as shown in fig. 6.28.

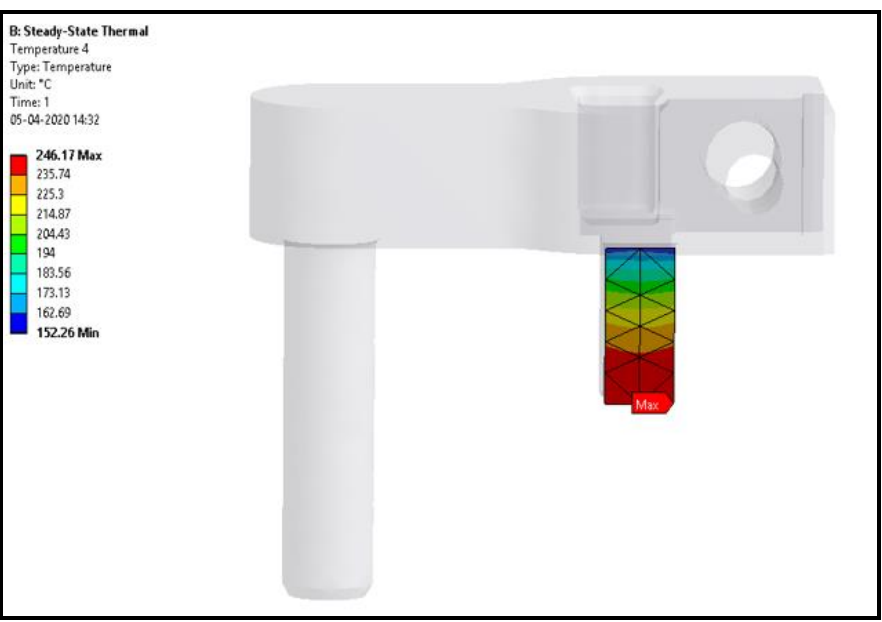

Fig. 6.28 Temperature of spring without heat shield 
The temperature of spring with heat shield is $80.78{ }^{\circ} \mathrm{C}$ as shown in fig. 6.29.

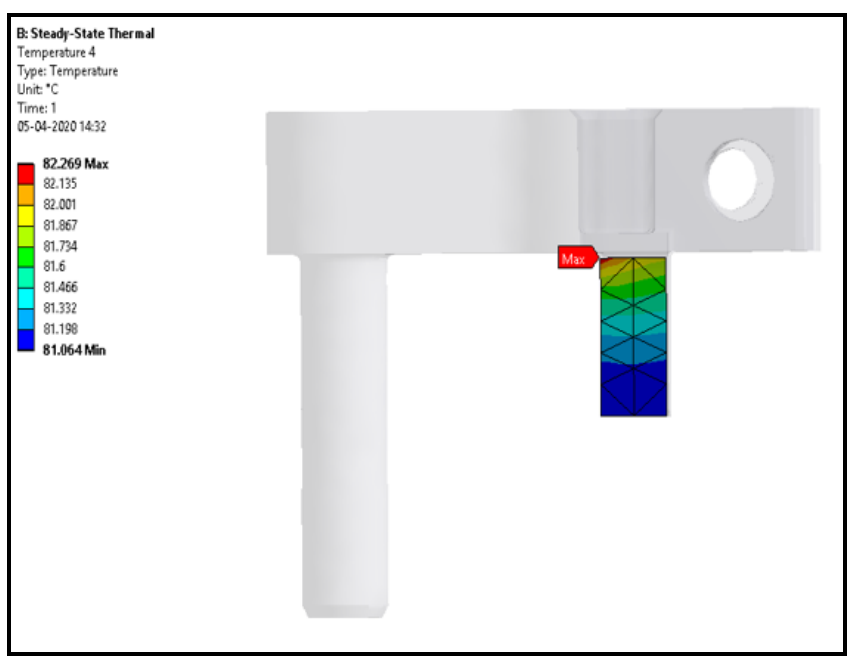

Fig. 6.29 Temperature of spring with heat shield

The temperature at the spring is reduced by $163^{\circ} \mathrm{C}$ after installation of heat shield for spring.

Conclusion:

The heat coming on the actuator and spring is reduced after installation of heat shield. So, working of actuator and spring may not get affected. The design of both heat shields are validated.

\section{CONCLUSION}

From this paper it is concluded that,

1. Multiple concepts were developed and based on the result of Pugh and CnE matrix for concept selection; best suitable concept for bracket and heat shield is selected.

2. By comparing the both values it is clear that value obtained from Ansys is greater than analytical value and thus system is safe as there are no chances of occurrence of resonant condition.

3. Also maximum equivalent stresses observed are close to the sharp edge in Ansys but in actual practice there will not be any sharp edge so, there will not be stress in bracket and both heat shield.

4. From steady thermal analysis it can be concluded that heat shield reduces the heat reaching to spring and actuator thus serves its purpose.

So, the design of bracket, heat shield of actuator and heat shield of spring are validated and they are safe.

\section{ACKNOWLEDGMENT}

The authors would like to thank Prof. P. D. Maskar and Prof. B. N. Naik for their guidance. Also thank Donald Willey, Ajay Vasudeo, PRC team, CTT Design Team and Structural Analysis Team, Cummins Technical Center India, Pune for providing technical support for this work.

\section{REFERENCES}

[1] Jeongwooo Lee, Cheolwoong Park, Yongrae Kim, Young Choi, Jongwon Bae, Byeungjun Lim "Effect of turbocharger on performance and thermal efficiency of hydrogen-fueled spark ignition engine" International Journal of Hydrogen Energy 44, (2019), pp. 4350-4360.

[2] Robin Holmbom, Bohan Liang, Lars Eriksson, "Implications of Using Turbocharger Speed Sensor for Boost Pressure Control " IFAC Papers Online 50-1,(2017), pp 11040-11045.

[3] N.R. Karthik and B. Gautam, "A Review on Turbocharger and Supercharger", International Journal of Emerging Trends in Engineering and Development, Issue 6, Vol. 5, (2016), pp. 2249-6149.

[4] P. Moulin, O. Grondin, J. Chauvin "Impact of EGR on Turbocharger Control on a Diesel Engine with two EGR loops" 6th IFAC Symposium Advances in Automotive Control Munich, Germany, 2010.

[5] M. Deligant, P. Podevin and G. Descombes, "CFD model for turbocharger journal bearing performances", Applied Thermal Engineering 31, (2011), pp. 811-819.

[6] A. Romagnolia, A. Manivannana, S. Rajoob, M.S. Chiong, A Feneleyc, A. Pesiridis, R.F. Martinez-Botasd "A review of heat transfer in turbochargers" Renewable and Sustainable Energy Reviews 79 (2017), pp. 1442-1460.

[7] Stainless steel 201, 201L, 202, 204 by Aalco

[8] Stainless steel: 1,4301 (304) and Sheet Plate (Quarto Plate and CPP) by Aalco.

[9] Durgesh Rathod, Snehal Pisal, ShrutikaKolambekar, Paxal Shah, Mr.K.S.Wangikar, "Design and Analysis of Sheet Metal Bending Machine" VJER-Vishwakarma Journal of Engineering Research, Issue 1, Volume 2, March 2018.

[10] J. E. Huber, N. A. Fleck and M. F. Ashby, "The selection of mechanical actuators based on performance indices", Department of Engineering, Cambridge University, Trumpington Street, Cambridge CB2 1PZ, UK.

[11] Nikhil Banerji, " The effect of radiation on ablative heat shields during atmospheric entry" EPFL scientific publication, (2017).

[12] Maheso Nakateko, Khumbulani Mpofu. "A learning factory concept for skills enhancement in rail car manufacturing industries", $9^{\text {th }}$ conference on learning factories. (2019), pp.187-193.

[13] Dr Stuart Burge, "The Systems Engineering Tool Box" Winston Churchill, (2009).

[14] https://www.mechanicalbooster.com/2017/08/how-turbochargerworks.html

[15] Cummins study material.

[16] L.C. Sleath, "The dimensional variation analysis of complex mechanical systems", EPSRC Pioneering research and skills, (2014).

[17] https://www.sigmetrix.com/case-studies-2/tolerance-analysis-casestudies-white-papers/variation-analysis-case-study-cummins-engine/ 
APPENDIX:

Table1: Pugh Matrix for Concept Selection:

\begin{tabular}{|l|c|c|c|c|c|}
\hline \multicolumn{1}{|c|}{ Criteria/Concept } & $\begin{array}{c}\text { Concepts } \\
\text { (Concept } \\
\text { P) }\end{array}$ & $\begin{array}{c}\text { Concept } \\
\text { A }\end{array}$ & $\begin{array}{c}\text { Concept } \\
\text { B }\end{array}$ & $\begin{array}{c}\text { Concept } \\
\text { C }\end{array}$ & $\begin{array}{c}\text { Concept } \\
\text { D }\end{array}$ \\
\hline Compact design & S & S & + & + & + \\
\hline $\begin{array}{l}\text { Protection of actuator from hot } \\
\text { radiations from outlet of } \\
\text { turbine housing }\end{array}$ & S & S & + & + & + \\
\hline $\begin{array}{l}\text { Protection of spring from hot } \\
\text { radiations from turbine } \\
\text { housing }\end{array}$ & S & S & - & + & + \\
\hline Time required for assembly & S & S & - & - & - \\
\hline Cost of system Total $\Sigma+$ & 0 & 0 & 2 & 3 & 3 \\
\hline Number of parts Total $\Sigma-$ & 0 & 0 & 3 & 2 & 2 \\
\hline Total $\Sigma$ S & 5 & 5 & 0 & 0 & 0 \\
\hline Total & 0 & 0 & -1 & 1 & 1 \\
\hline Rank & 3 & 3 & 5 & 1 & 1 \\
\hline
\end{tabular}

Table 2: Cause and Effect matrix for Concept Selection

\begin{tabular}{|c|c|c|c|c|c|c|c|c|}
\hline & $\begin{array}{c}\text { Rating of Importance to } \\
\text { Customer }\end{array}$ & 6 & 10 & 10 & 4 & 8 & 7 & \\
\hline & & 1 & 2 & 3 & 4 & 5 & 6 & \\
\hline \multicolumn{2}{|c|}{$\begin{array}{l}\text { Bracket and heat shield design } \\
\text { concepts }\end{array}$} & $\begin{array}{l}\overline{0} \\
\bar{y} \\
\frac{0}{0} \\
0 \\
\tilde{0}\end{array}$ & 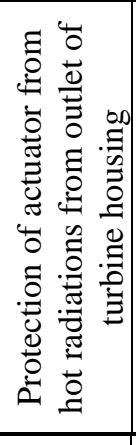 & 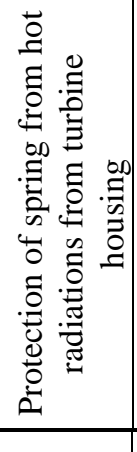 & 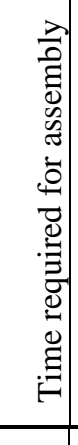 & 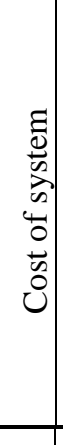 & 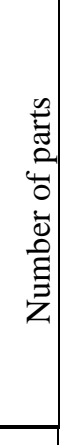 & Total \\
\hline Pictures of concept & Description of concept & & & & & & & \\
\hline
\end{tabular}




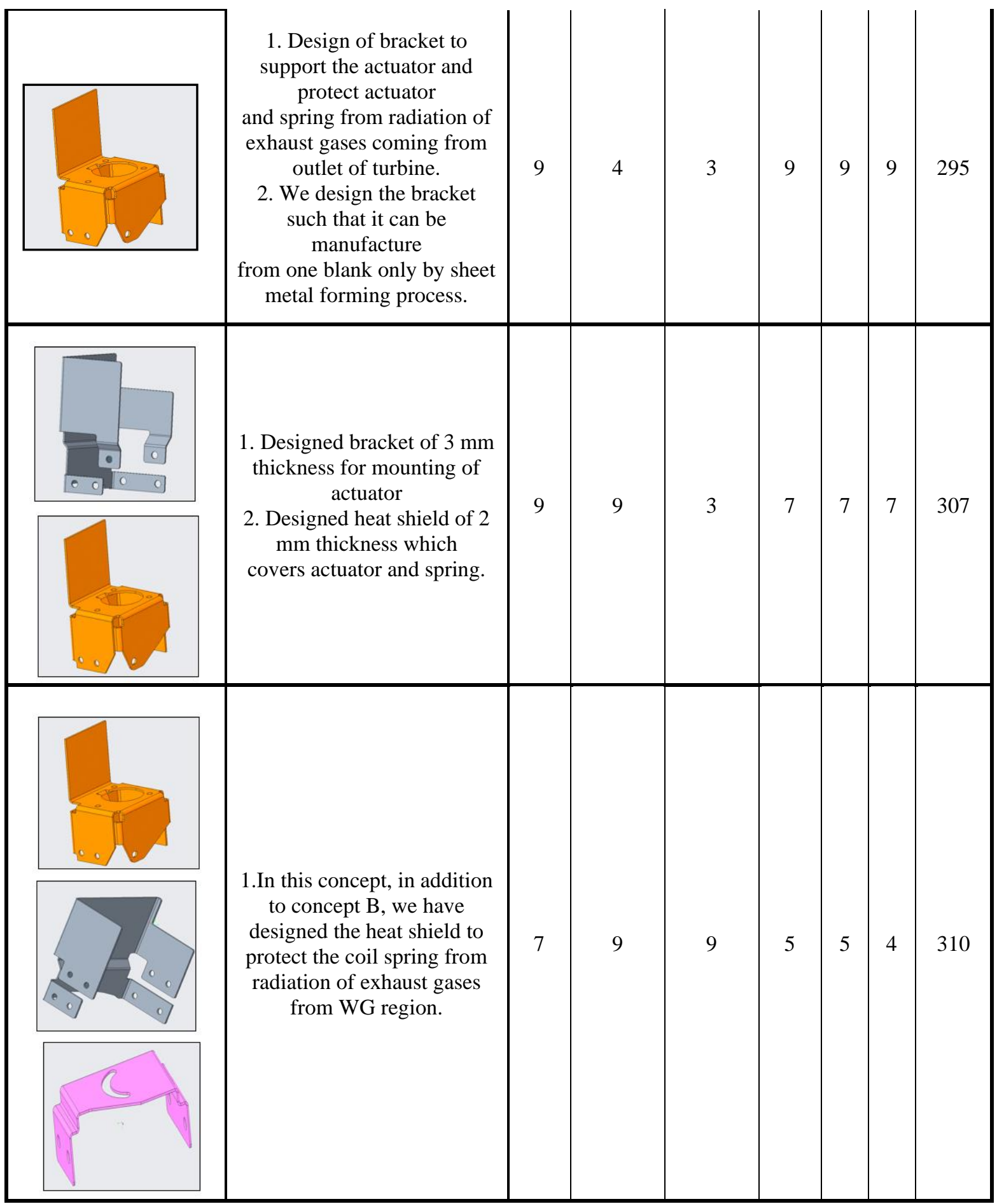




\begin{tabular}{|l|l|l|l|l|l|l|}
\hline & & & & & & \\
\hline
\end{tabular}

